\title{
The Cruciality of Using Literature to Enhance Reading Comprehension Skills
}

\author{
Dr. Khaled Hassan Ali Eltayb \\ Faculty of Arts. English Language Department \\ Omdurman Ahlia University
}

Sudan

khaledkenana66@yahoo.com

\begin{abstract}
This paper attempted to shade the light upon "The cruciality of teaching Literature to enhance reading comprehension skills", is conducted to find out the role and importance of teaching literature in developing comprehension skills in tertiary level. The researcher adopted descriptive analysis method, the population of this study of (30) English language teachers from different Sudanese universities. Date was gathered by questionnaire. The researcher used a statistical package for social studies (SPSS package). The study comes up with followings: Teaching literature in language courses helps students to develop Reading Comprehension skills, teaching literature in reading lessons helps students to develop skimming and scanning techniques, literature presents valuable material to teach reading comprehension lesson, literature is a good way to practice acquiring quick information from the texts, and teaching literature develops students' interpretative abilities.
\end{abstract}

Keywords: Literature; Reading Comprehension Skills; Skimming; Scanning. 


\section{Introduction of the Study}

English is an international language used as a second or, foreign language vastly throughout the world. In addition to its official function, it plays a significant role in the field of education. According to Yorkey, Richard, C, (2009:2) "For many university teachers of English as foreign language (EFL), the study of literature is indispensable, because it exposes students to meaningful context that are replete with descriptive language, and interesting characters. Structuring lessons around the reading of literature introduces of profound range of vocabulary, dialogues, and prose".

Using of literary works in the teaching of English has been a matter of concern for many years as part of search for better, more efficient and more constructive reading comprehension activities. Reading comprehension is one of the main important elements in English language learning for all students because it provides the basis for substantial amount of learning in education (Alvermann and Earle, 2003.12-30)

There is no doubt that literature can provide a context of language enrichment. Especially in the foreign language situation which exists in the Sudan - where learners of English are not exposed to as much language practice as possible in order to improve their standard of English. Thus, much of the vocabulary needed for smooth communication will be acquired from the literary works. Literature started to be viewed as an appropriate vehicle for language learning, and development since the focus is now on authentic language and authentic situation.

Teaching literature contributes generously to develop reading comprehension skills; it could be a promising field for researchers to carry out. Therefore, one of the study objectives is to improve reading skills through literature, how can literature be used with reading lesson and how useful to use literature in the classroom. 
In addition to developing students' reading skills, teaching literature also appeals to their imagination, develops cultural awareness and encourages critical thinking about plot, theme, and characters.

Statement of the Problem:

As an assistant professor at Omdurman Ahlia university, the researcher noticed the low standard of the students in reading comprehension skills, which leads to their low performance in the other skills and failure in academic achievement. Thus, the study aims to know to what extent literature contributes in developing reading comprehension skills at tertiary level. The study assumes that teaching reading comprehension through literature is essential and effective in tertiary level. Brumfit, C. J \& Carter, (1986:16) bolster this assumption, "To try to teach language without the help of literature is doomed to be ineffective.

Objectives of the Study

This Paper Aims to:

1- find out the role teaching literature in developing reading comprehension skills.

2- improve students comprehension skills

3- help course designers to introduce new text-books which solve the problem of reading comprehension skills.

Questions of the Study

This paper intends to answer the following questions:

1- To what extend does literature contribute in developing reading comprehension skills? 
2- To what extend does teaching literature in the classroom improving skimming and scanning skills?

Hypotheses of the Study

The researcher prepared the following assumptions that based on the paper questions:

Teaching literature contributes positively in developing reading comprehension skills.

Teaching literature develops students' reading strategies in terms of skimming and scanning.

\section{Significance of the Study}

This study is important, because it deals with reading comprehension skills difficulties faced by Sudanese university students. The importance of this study comes from its attempt to suggest ways of developing comprehension skills through literature. The find of this study might be used by university teachers in helping their students to acquire that skill.

\section{Limitation of the Study}

This study is limited to the impact of using literature to develop reading comprehension skills, at Omdurman Ahlia University.

\section{Methodology}

The researcher adopts descriptive analysis approach. The subject in this study is Omdurman Ahlia University students - first academic year.

The instrument used in this study is written questionnaire for Sudanese university English language teachers. 
The Purposes of Teaching Literature:

When literature is discussed for the purpose of teaching we need to draw a distinction between whether literature is for study or used as resource.

\section{Literature for Study:}

In some of courses or classes where literature is taught as a separate subject and literature itself is the content of the course, the focus of the teaching and learning is on the literary features. This kind of approach examines the history and characteristics of literary movements; the social, political, and historical background to a text etc. Lazar, $(1993 ; 35)$ this is purely the area of literature teaching and not language teaching Langer (1991:3) in this connection put, "It involves a considerable baggage of critical concepts, literary conventions and metalanguage and the requirement is often that students should show an ability to use such terms and concepts in talking and writing about literature.

\section{Literature as a Resource}

Literature is a legitimate and valuable resource for language teaching. Rura, N (2007:4) mentions that there should be language focus of the literature texts. Literary texts are treated as if they were also written for language teaching. The advantages of teaching literature for language activities are numerous. To achieve these advantages, different text of the literature should be planned well and effectively. In the language classroom one has to teach the understanding of literature which come before its appreciation. Therefore, question should be made and accumulated one after another so that students can graph the main idea of the text. Questions should be designed so that responses from the students lead them to understand the content of the texts. 
Teaching Language through Literature:

Literature occupies an important place in language classroom. A language teacher presents the literary texts from linguistic point of view. Literature, which accepts language as its raw materials, is not only the mode of expression, vehicle for thought but also a useful and effective resource of the language teaching and helps the learners in fostering their language skills Langer, J (1991) writes, "There is no other way of acquiring a sophisticated common of language except through assiduous study of literature". In the words of Aucarman,C.R (1981), " the best road of language proficiency lies in its literature; nothing is so emotional gripping so that it is remembered for a long time" these views clarify that literature and language need to be placed side - by-side and taught in integration.

The values of teaching literature in class room

There is a wide educational value of literature teaching and learning. Studying of literature helps students in an understanding of English language and of its structure, vocabulary and syntax. There is no other way of acquiring the sophisticated command of language except through studying of its literature. Presupposing that literature can be useful tool for language teaching. The following are some of the reasons why literature should be incorporated as a part of curriculum in the language teaching program:

\section{Motivating Material}

Literature deals with topics, which are fundamentally interesting, as they are about human experience and are designed to engage the readers' attention. Lazar,(1993:16) writes, "A good novel or short story may be particularly gripping in that it involves students in complicated dilemmas. A poem may elicit a powerful emotional response from students," 


\section{Access to Cultural Background}

Students acquire and grasp new and strong information about the culture they are not familiar with by studying literature. Lazar (1993:16) "literature can provide students access to culture of people whose language they are studying. The researcher thinks "literature will increase all language skills, because literature extends linguistic knowledge by giving evidence of extensive and subtle vocabulary usage and exact syntax".

\section{Developing Students' Interpretative Abilities}

Because literature is highly suggestive and associative, it speaks different people in the same or different contexts. The readers do not react to the text in the same way. Each literary text has multiple meanings or interpretations as each person has different perceptions. In this sense, literature invites interactive discussions in the class. This is because literary texts are often rich multiple levels of the meanings, and demand that the readers/learners be actively involved in teasing out the unstated implications and assumptions of the text according to Lazar, (1993:19) literature assists students to enhance and develop their interpretative abilities when they are given opportunities to interpret such texts. They develop their awareness by finding their own interpretations based on the evidence on the text.

\section{Educating the Whole Person}

Literature gives awareness and insight to students by encouraging them to reading the texts written by different writers. As they show their love for literature, they are rewarded themselves in deep satisfaction and lasting pleasure. According Langer, J (1991:9) "Stimulating students to learn literature is helping them go grow as individuals as well as their relationship with the people and students around them". Teaching literature helps students understand and appreciate cultures and believes different from their own. Students 
are given access to a world attitude, collective imaginings, and historical frame of reference that constitutes the memory of people speech community; therefore literature and culture are inseparable. Literature is genuine or authentic material.

The reasons for using literature in the language classroom cannot be restricted to these points. However, these are some of the major issues about this topic.

Analysis of Questionnaire:

The first hypothesis

"Using literature contributes positively in developing reading comprehension skills"

Statement No\#1 "literature positively contributes in developing reading comprehension skill.

Table (1-1)

The frequency distribution for respondents' answer about statement

\begin{tabular}{|l|l|l|}
\hline Valid & Frequency & Percent \\
\hline Strongly agree & 25 & 83.3 \\
\hline Agree & 5 & 16.7 \\
\hline Total & 30 & 100.0 \\
\hline
\end{tabular}

Statement\#1 figure (1) shows that (25) teachers (83.3) strongly agree Literature positively contributes in developing comprehension skill, there also (5) teachers (16.7\%) agree on that. This analysis shows the majority of teachers (strongly agree) this indicates that, teachers agree with this statement.

Statement No\#2 "Literature may motivate students to read effectively."

Table (1-2)

The frequency distribution for the respondents' answer about statement

\begin{tabular}{|l|l|l|}
\hline valid & Frequency & Percent \\
\hline Strongly agree & 14 & 46.7 \\
\hline
\end{tabular}




\begin{tabular}{|l|l|l|}
\hline Agree & 16 & 53.3 \\
\hline Total & 30 & 100.0 \\
\hline
\end{tabular}

Statement \#2 figure (2) shows that (14) teachers (46.7\%) strongly agree that Literature may motivate students to reading effectively, there are also (16) teachers (53.3\%) agree on that. This analysis shows that all teachers choose (strongly/agree) this indicates that, teachers agree with this statement.

Statement No \#3 "Using Literature in reading comprehension lesson is time consuming"

Table (1-3)

The frequency distribution for the respondents' answer about statement

\begin{tabular}{|l|l|l|}
\hline valid & Frequency & Percent \\
\hline Strongly agree & 5 & 16.7 \\
\hline Agree & 6 & 20.0 \\
\hline Not sure & 6 & 20.0 \\
\hline Disagree & 10 & 33.3 \\
\hline Strongly disagree & 3 & 10.0 \\
\hline Total & 30 & 100.0 \\
\hline
\end{tabular}

Statement \#3 figure (3) shows that (10) teachers (33.3) disagree, and (3) teachers (10\%) disagree that using literature in reading comprehension lesson is time consuming. This analysis shows the majority of teachers (strongly disagree) this indicates that, teachers agree with this statement.

Statement No \#4 literature develops students' interpretative abilities.” 
Table (1-4)

The frequency distribution for the respondents' answer about statement

\begin{tabular}{|l|l|l|}
\hline valid & Frequency & Percent \\
\hline Strongly agree & 8 & 26.7 \\
\hline Agree & 18 & 60.0 \\
\hline Not sure & 1 & 3.3 \\
\hline Disagree & 3 & 33.3 \\
\hline Strongly disagree & 3 & 10.0 \\
\hline Total & 30 & 100.0 \\
\hline
\end{tabular}

Statement \#4 figure (4) shows that (8) teachers (26.7\%) strongly agree with that literature develops students' interpretative abilities, there also (18) teachers $(60.0 \%)$ agree on that. This analysis shows the majority of teachers (strongly agree) this indicates that, teachers agree with this statement.

Statement \#5 Literature can represent valuable authentic material”.

Table (1-5)

The frequency distribution for the respondents' answer about statement

\begin{tabular}{|l|l|l|}
\hline valid & Frequency & Percent \\
\hline Strongly agree & 18 & 60.0 \\
\hline Agree & 8 & 26.7 \\
\hline Not sure & 1 & 3.3 \\
\hline Strongly disagree & 3 & 10.0 \\
\hline Total & 30 & 100.0 \\
\hline
\end{tabular}


Statement \#5 figure (5) shows that (18) teachers (60.0\%) strongly agree that literature can represent valuable authentic material there are also (8) teachers (26.7\%) agree on that. This analysis shows the majority of teachers (strongly agree) this indicates that, teachers agree with this statement.

Statement \#6 "Teaching Literature decreases reading ability"

Table (1-6)

The frequency distribution for the respondents' answer about statement

\begin{tabular}{|l|l|l|}
\hline valid & Frequency & Percent \\
\hline Strongly agree & 2 & 6.7 \\
\hline Agree & 1 & 3.3 \\
\hline Not sure & 3 & 10.0 \\
\hline Disagree & 13 & 43.3 \\
\hline Strongly disagree & 11 & 36.0 \\
\hline Total & 30 & 100.0 \\
\hline
\end{tabular}

Statement \#6 figure (6) shows that (13) teachers (43.3) strongly disagree that Teaching decreases reading speed ability, there are also (11) teachers $(36.7 \%)$ disagree on that. This analysis shows the majority of teachers (strongly agree) this indicates that, teachers agree with this statement.

Statement \#7 “Literature may arouse students' comprehension in reading lessons"

Table (1-7)

The frequency distribution for the respondents' answer about statement

\begin{tabular}{|l|l|l|}
\hline valid & Frequency & Percent \\
\hline Strongly agree & 11 & 36.7 \\
\hline Agree & 16 & 53.3 \\
\hline Not sure & 2 & 6.7 \\
\hline
\end{tabular}




\begin{tabular}{|l|l|l|}
\hline Disagree & 1 & 3.3 \\
\hline Total & 30 & 100.0 \\
\hline
\end{tabular}

Statement \#7 figure (7) shows that (11) teachers (36.7\%) strongly agree that literature may arouse students' comprehension in reading lessons", there also (16) teachers $(53.3 \%)$ agree on that. This analysis shows the majority of teachers strongly agree, this indicates that, teachers agree with this statement

The Second Hypothesis

Using literature develops students' reading strategies in term of skimming and scanning.

Statement \#8 “using literature is an excellent way to develop the scanning technique.

Table (1-8)

The frequency distribution for the respondents' answer about statement

\begin{tabular}{|l|l|l|}
\hline valid & Frequency & Percent \\
\hline Strongly agree & 11 & 36.7 \\
\hline Agree & 16 & 50.0 \\
\hline Not sure & 4 & 13.3 \\
\hline Total & 30 & 100.0 \\
\hline
\end{tabular}

Statement \#8figure (9) shows that (11) teachers (36.7\%) strongly agree that using literature is an excellent way to develop the scanning technique", there also (15) teachers (50.0\%) agree on that. This analysis shows the majority of teachers strongly agree, this indicates that, teachers agree with this statement.

Statement \#9 “literature encourages students to adopt proper habits of fluent reading." 
Table (1-10)

The frequency distribution for the respondents' answer about statement

\begin{tabular}{|l|l|l|}
\hline valid & Frequency & Percent \\
\hline Strongly agree & 13 & 43.3 \\
\hline Agree & 14 & 46.7 \\
\hline Not sure & 2 & 6.7 \\
\hline Disagree & 1 & 3.3 \\
\hline Total & 30 & 100.0 \\
\hline
\end{tabular}

Statement \#9 figure (10) shows that (13) teachers (43.3\%) strongly agree that literature encourages students to adapt proper habits of fluent reading, there also (14) teachers $(46.7 \%)$ agree on that. This analysis shows the majority of teachers strongly agree, this indicates that, teachers agree with this statement.

Statement \#10 "literature enables students to read fast."

Table (1-11)

The frequency distribution for the respondents' answer about statement

\begin{tabular}{|l|l|l|}
\hline Valid & Frequency & Percent \\
\hline Strongly agree & 17 & 56.7 \\
\hline Agree & 10 & 33.3 \\
\hline Not sure & 2 & 6.7 \\
\hline Disagree & 1 & 3.3 \\
\hline Total & 30 & 100.0 \\
\hline
\end{tabular}

Statement \#10figure (11) shows that (17) teachers (56.7\%) strongly agree that literature enables students to read fast", there also (10) teachers (33.3\%) agree on that. This analysis shows the majority of teachers strongly agree, this indicates that, teachers agree with this statement. 
Statement \#11. "The skimming technique can be developed through using literature."

Table (1-12)

The frequency distribution for the respondents' answer about statement

\begin{tabular}{|l|l|l|}
\hline Valid & Frequency & Percent \\
\hline Strongly agree & 12 & 40.0 \\
\hline Agree & 14 & 46.7 \\
\hline Not sure & 4 & 13.3 \\
\hline Total & 30 & 100.0 \\
\hline
\end{tabular}

Statement \#11 figure (12) shows that (12) teachers (40.0\%) strongly agree that the skimming technique can be developed through using literature", there also (14) teachers (46.7\%) agree on that. This analysis shows the majority of teachers strongly agree, this indicates that, teachers agree with this statement.

Statement $\# 12$. "Literature is a good way to practice acquiring quick information from the texts."

Table (1-13)

The frequency distribution for the respondents' answer about statement

\begin{tabular}{|l|l|l|}
\hline Valid & Frequency & Percent \\
\hline Strongly agree & 11 & 36.7 \\
\hline Agree & 17 & 56.7 \\
\hline Not sure & 1 & 3.3 \\
\hline Disagree & 1 & 3.3 \\
\hline Total & 30 & 100.0 \\
\hline
\end{tabular}

Statement \#12 figure (13) shows that (11) teachers (36.7\%) strongly agree that literature is a good way to practice acquiring quick information from the texts" there also (17) teachers 
(56.7\%) agree on that. This analysis shows the majority of teachers strongly agree, this indicates that, teachers agree with this statement.

Conclusion:

The aim of this study is to find out the cruciality of using literature to develop Reading Comprehension Skills. Teaching helps students to understand conventions of target community as well as developing language - learning process. The study investigates that areas where literature can play a vital role as well as model of teaching language in general and reading comprehension skills in particular, that literature has an educational value and the view of literature as schemata for understanding the whole world. 


\section{References}

Alvermann, D, \&Earle,J (2003)- Comprehension Instruction. In A.P- sweet, \& C. Snow Aucarman, C.R (1981) How Do I Teaching Reading? University R. Hod Island.

Brumfit, C. J \& Carter R-A. (Eds.) (1986). Literature and language teaching. Oxford University Press.

Langer, J.(1991), literacy Acquisition through literature. Journal of Adolescent and Adult Study, 40, 602- 614 .

Lazar, Gillian. (1993) Language and Language Teaching London: CUP.

Rura, N.(2007) The Encyclopedia of Education Volume 12. Macmillan.

Yorkey, Richard, C. (2009) Study Skills for students of English second. McGraw- Hill, New York 